\title{
Equilibrium, Kinetics and Thermodynamic of Dye Adsorption by Low - Cost Adsorbents
}

\author{
S. Sawasdee and P. Watcharabundit
}

\begin{abstract}
This work is to study the adsorption of a commercial dye (magenta color) for silk yarn by low-cost adsorbents such as green perlite and shrimp shell (Macrobrachium rosenbergii). The adsorption experiments were carried out in batch process without adjusting $\mathrm{pH}$. The various parameters, such as contact time, initial dye concentration and adsorbent doses were evaluated at the natural $\mathrm{pH}$. The equilibrium data at various concentrations were analyzed using Langmuir, Freundlich and Temkin isotherms. The results showed that the maximum adsorption capacities of Langmuir isotherm valued $14.805 \mathrm{mg} / \mathrm{g}$ for green perlite and $5.621 \mathrm{mg} / \mathrm{g}$ for shrimp shell at $30^{\circ} \mathrm{C}$. The kinetic data was better fitted with pseudo-second order for the adsorbents. Thermodynamic properties such as free energy $(\Delta G)$, enthalpy $(\Delta H)$ and entropy $(\Delta S)$ indicated spontaneous and endothermic in nature of adsorption for all adsorbents. The study revealed that green perlite and shrimp shell can be used as an efficient adsorbents for the removal of dye solution.
\end{abstract}

Index Terms -Adsorption isotherm, kinetic, thermodynamic, low-cost adsorbents.

\section{INTRODUCTION}

Synthetic dyes are used for dying wool, cotton, nylon, silk and modified acrylics. It is estimated that $10-15 \%$ of the dyes are lost in the dye effluent during such dyeing processes [1]. The presence of dyes can cause damage to living beings in water. In addition, the stability of most dye molecules under condition of light, heat and chemicals leads to the fact that the dying effluents are difficult to degrade [2]. Many treatment system have been used for the removal of synthetic dyes from aqueous solutions including ion exchange, membrane filtration, precipitation, photocatalytic degradation, oxidation, electrochemical and adsorption. Among several dye removal techniques, adsorption is an efficient one to remove different kinds of dyes from water and wastewater [3] and it has wide applicability in wastewater treatment [4]. This process is simple to design, easy to operate, cost effective, eco-friendly and insensitive toxic substances. Activated carbon is the most efficient and popular adsorbent and has been used with the great success [5] because of high surface area, high adsorption capacity, but it is relatively high price and difficult to regenerate. Therefore, much attention has recently been paid in seeking cheap, locally available and effective adsorbent [6].

Natural adsorbents such as agricultural waste, waste food or low-cost inorganic material have been most popular for

Manuscript received January 14, 2015; revised March 17, 2015.

The authors are with the Faculty of Science and Technology, Thepsatri Rajabhat University, Lopburi, Thailand (e-mail: ps_neng@hotmail.com, prachartw@hotmail.com). wastewater treatment due to availability and low- cost adsorbent. Recently, these have been alternative natural adsorbents for treatment of dye wastewater such as peanut hull [7], bentonite from China [8], [9], diatomite from Jordan [1] and shrimp shell [3] etc.

The purpose of this work was to study the adsorption of a synthetic dye for silk yarn on low-cost adsorbents namely, green perlite and shrimp shell. The equilibrium study was investigated to observe the effects of various adsorption parameters such as contact time, adsorbent dose and initial dye concentration on the process. Adsorption data were analyzed using Langmuir, Freundlich and Temkin adsorption isotherm models. Moreover, the kinetic and thermodynamic studies were investigated.

\section{EXPERIMENTAL}

\section{A. Adsorbents Preparation}

Green perlite was collected from Sa Bot, Lopburi, Thailand. It was removed all dirt by double distilled water and dried in an hot air oven at $100^{\circ} \mathrm{C}$ for $24 \mathrm{~h}$.

Shrimp shell was obtained from fresh food market in Lopburi City, Thailand. It was removed all dirt by double distilled water and dried in an hot air oven at $80^{\circ} \mathrm{C}$ for $24 \mathrm{~h}$.

Particle size all adsorbents were ground and sieved to particle size 50-100 mesh and stored in a dessicator until use.

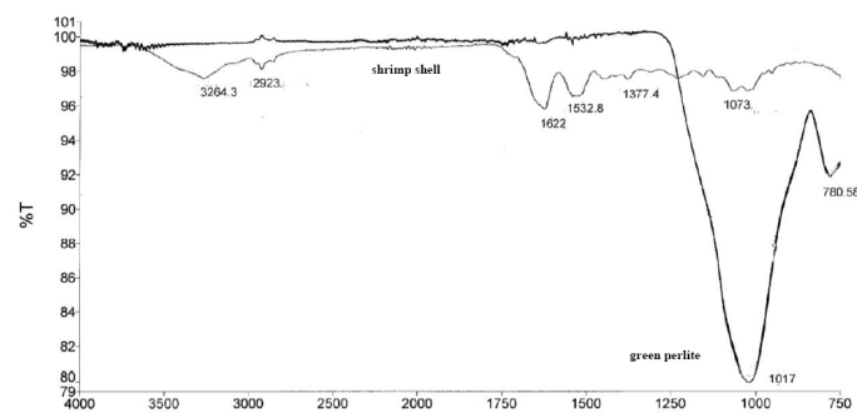

Fig. 1. FTIR of green perlite and shrimp shell.

\section{B. Adsorbate Preparation}

Adsorbate is a commercial synthetic dye for silk yarn. Its color is magenta and its brand is "Cats run around the World" (Thailand). It was obtained from a local shop in Lopburi, Thailand. The dye was used as such without further purification. It was dried at $80^{\circ} \mathrm{C}$ for $2 \mathrm{~h}$ before use. The stock solution was prepared by dissolving a constant mass of dye in double distilled water to achieve the concentration of 100 $\mathrm{mg} / \mathrm{L}$ and subsequently diluted to the required concentrations. The $\mathrm{pH}$ of its solution at $20 \mathrm{mg} / \mathrm{L}$ is 7.85 . Absorbance value of dye solution was measured by a double beam UV-Vis 
spectrophotometer (Analytik Jena, Specord 210 plus) and dye concentration was determined by comparing with its calibration curve at the wavelength $548 \mathrm{~nm}$.

\section{Characterization of Adsorbents}

The surface functional groups of adsorbents were analysed by FTIR (Perkin Elmer model two) and the spectra were recorded from $4000-750 \mathrm{~cm}^{-1}$.

\section{Batch Experiment Adsorption}

Various adsorption parameters, such as contact time, adsorbent dose and initial dye concentration were evaluated. The $\mathrm{pH}$ of the solution was not adjusted. Adsorption experiments were carried out in $250 \mathrm{ml}$ Erlenmeyer flasks by known mass of adsorbent, $100 \mathrm{ml}$ of dye solution under an isothermal shaker $\left(30 \pm 1^{\circ} \mathrm{C}\right)$ and agitation speed $250 \mathrm{rpm}$. Then, the suspended matter in each sample was filtered and supernatant was measured for dye concentration by the double beam UV-Vis spectrophotometer at $548 \mathrm{~nm}$. The amount of adsorption capacity $(q)$ and percentage of adsorption were calculated as follows:

$$
\begin{gathered}
q=\frac{\left(C_{\mathrm{o}}-C_{t}\right) V}{W} \\
\% \text { adsorption }=\frac{\left(C_{\mathrm{o}}-C_{t}\right)}{C_{\mathrm{o}}} \times 100
\end{gathered}
$$

When $C_{\mathrm{O}}$ and $C_{t}(\mathrm{mg} / \mathrm{L})$ are dye concentrations at the initial and any time $(t, \min ) . V(L)$ is the volume of the solution, $q(\mathrm{mg} / \mathrm{g})$ is the amount adsorbed at any time $(t, \mathrm{~min})$ and $W(\mathrm{~g})$ is the mass of adsorbent.

\section{RESUltS AND DiscUSSIONS}

\section{A. Characterization of Adsorbents}

FTIR spectra of green perlite and shrimp shell have shown in Fig. 1 The peak from green perlite around $1017 \mathrm{~cm}^{-1}$ due to siloxane ( $\mathrm{Si}-\mathrm{O}-\mathrm{Si}$ ) and $794 \mathrm{~cm}^{-1}$ correspond to $\mathrm{SiO}-\mathrm{H} \mathrm{[10].}$ The peak from shrimp shell around $3264.3 \mathrm{~cm}^{-1}$ due to the stretching of $\mathrm{OH}$ group overlapping stretching band of $\mathrm{N}-\mathrm{H}$ [11]. The peak of $1622 \mathrm{~cm}^{-1}$ correspond to the bending in plane of $\mathrm{N}-\mathrm{H}$. The band at $1073 \mathrm{~cm}^{-1}$ is assigned to $\mathrm{C}-\mathrm{N}$ bending [12].

\section{B. The Effect of Contact Time}

Fig. 2 shows the effect of contact time of dye adsorption on green perlite $(0.6 \mathrm{~g})$ and shrimp shell $(1.0 \mathrm{~g})$ at the initial concentration $20 \mathrm{mg} / \mathrm{L}$. The plot of adsorption capacity (q) versus the contact time for initial dye concentration $20 \mathrm{mg} / \mathrm{L}$ is shown in Fig. 2. The removal of dye was rapid at the initial stage of contact time and gradually decreased with time until equilibrium. The rapid adsorption observed during the first 30 min was probably due to the abundant availability of active sites on the adsorbents surface, and with the gradual occupancy of these sites, the adsorption became less efficient It appeared that the contact time needed to reach equilibrium conditions were $180 \mathrm{~min}$ and $30 \mathrm{~min}$ for green perlite and shrimp shell, respectively. The contact time of adsorption in this experiment is accordance with the results obtained in dye adsorption experiments onto different types of adsorbents as for example, Ca-bentonite [13], shell of Penaeus indicus shrimp [3]. The adsorption capacity increased with an increase in the contact time and was constant at the equilibrium time. The equilibrium capacities of adsorption were $3.077 \mathrm{mg} / \mathrm{g}$ and $1.840 \mathrm{mg} / \mathrm{g}$ onto green perlite and shrimp shell.

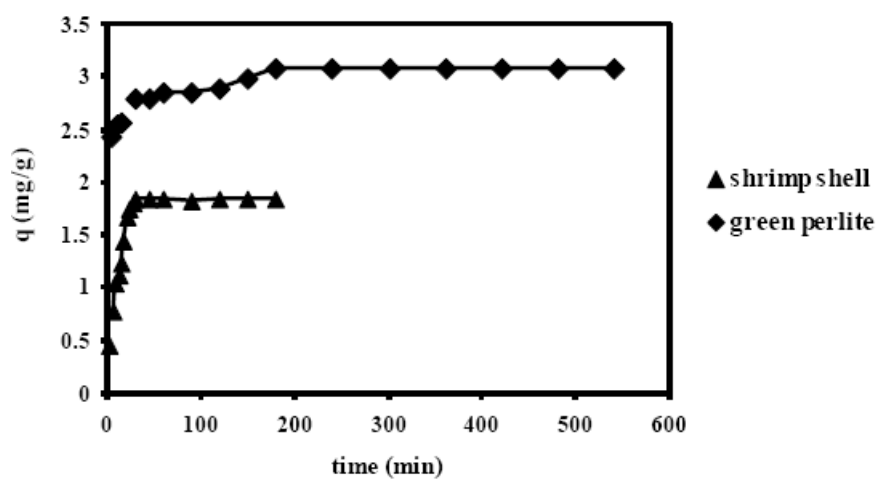

Fig. 2. effect of contact time on dye adsorption.

\section{Effect of Adsorbent Doses}

The equilibrium adsorption of dye on green perlite and shrimp shell was investigated at $30^{\circ} \mathrm{C}$ by varying the adsorbent amount from $0.20 \mathrm{~g}$ to $1.00 \mathrm{~g}$ of green perlite and from $0.60 \mathrm{~g}$ to $2.00 \mathrm{~g}$ of shrimp shell. Fig. 3 shows the plot of percentage of adsorption against the adsorbent doses at the initial dye concentration $20 \mathrm{mg} / \mathrm{L}$. The results were shown that the percentage of dye adsorption was $75.10-95.21 \%$ for green perlite and $38.82-75.07 \%$ for shrimp shell. The percentage of adsorption increased with an increase in adsorbent dose $(\mathrm{g})$ due to increase binding site at higher amount of adsorbent [14]. However, it was observed that the rate of dye removal percentage slightly decreased as the adsorbent dose increased. It was due to the presence of higher amount of adsorbent in dye solution resulting in reduced distances between the adsorbent particles, thus making many binding sites unoccupied (15).

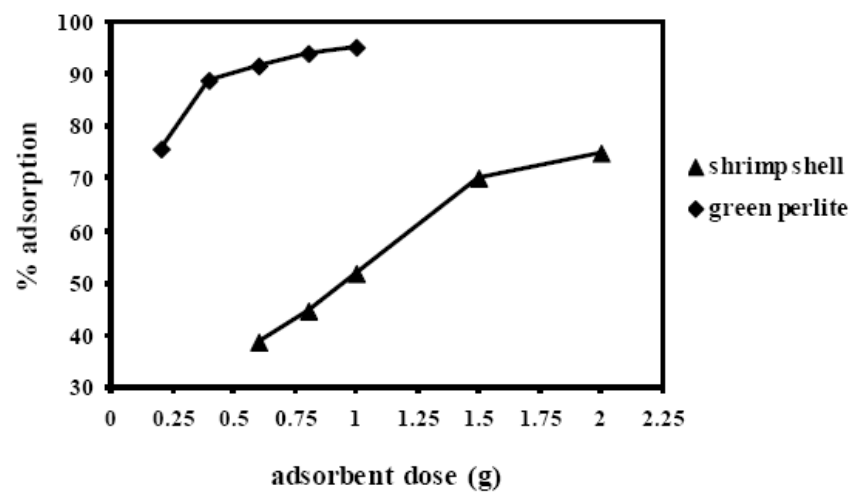

Fig. 3. effect of adsorbent dose on dye adsorption

\section{Adsorption Isotherm}

Equilibrium isotherm equations are used to describe experimental adsorption data. The equation parameters of these equilibrium models often provide some insight into both the sorption mechanism and the surface properties and 
affinity of the adsorbent. Therefore, the best-fit isotherm is required for the adsorption system.

The Langmuir model is the most widely used isotherm equation. It assumes that equilibrium is attained when a monolayer of the adsorbate molecules saturates the adsorbent. The Langmuir isotherm in nonlinear and linear form are represented as follows:

$$
\begin{gathered}
q_{e}=\frac{q_{m} K_{L} C_{e}}{1+K_{L} C_{e}} \\
\frac{C_{e}}{q_{e}}=\frac{1}{q_{m}} C_{e}+\frac{1}{K_{L} q_{m}}
\end{gathered}
$$

When $C_{e}(\mathrm{mg} / \mathrm{l})$ is the equilibrium concentration, $q_{e}$ $(\mathrm{mg} / \mathrm{g})$ is the amount adsorbed at equilibrium, $K_{L}$ is the Langmuir constant and $q_{\max }(\mathrm{mg} / \mathrm{g})$ is the maximum adsorption capacity. The values of $q_{\max }$ and $K_{L}$ are calculated from the slope and intercept of the straight line plotting of $C_{e} / q_{e}$ versus $C_{e}$.

The essential characteristics of a Langmuir isotherm can be expressed in terms of a dimensionless separation factor or equilibrium parameter, $R_{L}$ which is defined by

$$
R_{L}=\frac{1}{1+K_{L} C_{O}}
$$

When $C_{\mathrm{O}}=$ initial dye concentration $(\mathrm{mg} / \mathrm{L})$ and $K_{L}=$ Langmuir constant $(\mathrm{L} / \mathrm{mg})$. The value of $R_{L}$ indicates the shape of the isotherm to be either unfavorable $\left(R_{L}>1\right)$, linear $\left(R_{L}=1\right)$, favorable $\left(0<R_{L}<1\right)$ or irreversible $\left(R_{L}=0\right)$.

The Freundlich isotherm describes equilibrium on heterogeneous surfaces and hence does not assume monolayer capacity. The Freundlich isotherm in nonlinear and linear form are represented as follows:

$$
\begin{gathered}
q_{e}=K_{F} C_{e}^{1 / n} \\
\log q_{e}=\log K_{F}+1 / \mathrm{n} \log C_{e}
\end{gathered}
$$

When $K_{F}$ is the adsorption capacity and $1 / n$ is the adsorption intensity. $1 / n$ and $K_{F}$ are calculated from slope and intercept of the Freundlich plot. It has been shown that $1 / n$ value between 0 and 1 represents a good adsorption. A value for $1 / n$ below one indicates a normal Langmuir isotherm while $1 / n$ above one is indicative cooperative adsorption [14].

The Temkin isotherm assumes that the heat of adsorption of all the molecules in a layer decreases linearly with surface coverage of the adsorbent due to sorbate-adsorbate interactions. This adsorption is characterized by a uniform distribution of binding energies. The nonlinear and linear form of the Temkin isotherm can be expressed as follows:

$$
q_{e}=B \ln \left(A_{T} \cdot C_{e}\right)
$$

$$
\begin{aligned}
& \text { When } B=\frac{R T}{b_{T}} \\
& \qquad q_{e}=\frac{R T}{b_{T}} \ln A_{T}+\frac{R T}{b_{T}} \ln C_{e}
\end{aligned}
$$

When $B$ is the Temkin constant related to heat of sorption. $A_{T}(\mathrm{~L} / \mathrm{mg})$ is the Temkin isotherm constant, $b_{T}(\mathrm{~J} / \mathrm{mole})$ is a constant related to the heat of adsorption, $R$ is the universal gas constant $(8.314 \mathrm{~J} / \mathrm{mol})$ and $\mathrm{T}$ is the absolute temperature (K).

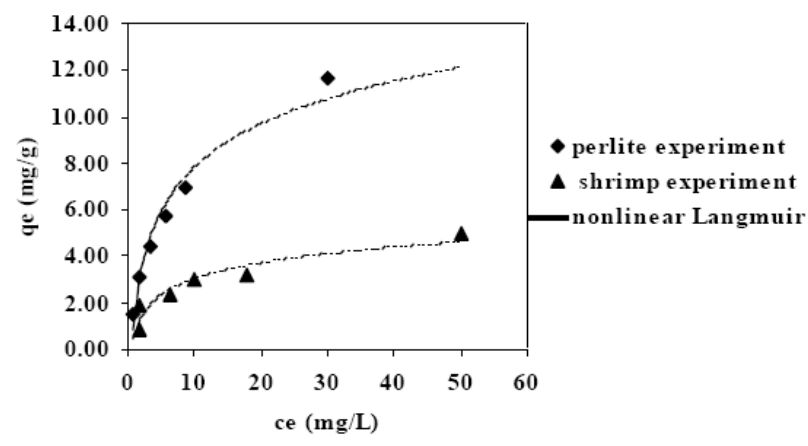

Fig. 4. Isotherm of adsorption.

The isotherm constants $b_{T}$ and $A_{T}$ are calculated from the slope and intercept of the $q_{e}$ versus $\ln _{C_{e}}$ plot.

Fig. 4 shows plot of experimental data between $q_{e}$ versus $C_{e}$ using nonlinear Langmuir equation with Excel solver. The results showed the adsorption capacity increased with increase in initial dye concentration. The initial dye concentration provides an important driving force to overcome all mass transfer resistances of the surface adsorbent between the aqueous and solid phases. Also, as the adsorption process precedes the driving force decrease with time, indicating that there is a saturation limit for the adsorbents [15]. Similar observations were reported by adsorption of cadmium on sugarcane bagasse [16], adsorption of chromium (VI) by ethylenediamine-modified cross-linked magnetic chitosan resin [17], adsorption of anionic dye on natural untreated clay [18].

Fig. 5 and Table I show values of three isotherms investigated at initial dye concentrations of 10-100 mg/L.

The experimental data were described by Langmuir, Freundlich and Temkin isotherms. Due to the linear correlation coefficient, the experiment data of dye adsorption onto green perlite and shrimp shell were better fitted by Langmuir than Freundlich and Temkin isotherms as in Table I. The results indicated the homogeneous nature by the monolayer coverage on surface between sorbed molecule and the maximum adsorption capacity valued $14.085 \mathrm{mg} / \mathrm{g}$ for green perlite and $5.621 \mathrm{mg} / \mathrm{g}$ for shrimp shell. Similar observation was reported by adsorption of anionic dyes onto natural untreated clay [18]. The effect of Langmuir isotherm shape could be used to predict whether adsorption system favorable or unfavorable. The separation factor $\left(R_{L}\right)$ of adsorption onto green perlite and shrimp shell valued 
$0.071-0.277$ and $0.071-0.278$, respectively. The value of $0<$ $R_{L}<1$ indicated that the adsorption of dye on adsorbent was favorable. For this work, the adsorption of dye onto green perlite and shrimp shell was favorable. From Freundlich isotherm, the valued for $1 / n$ below one indicated a normal Langmuir isotherm and reflected the favorable adsorption [19]. And the value of $R T / b_{T}$ (less than $20 \mathrm{~kJ} / \mathrm{mol}$ ) which is an indication of heat of adsorption obtained from Temkin isotherm indicated the adsorption was physi-sorption [20]. Similar observation was reported by the adsorption of malachite green onto bentonite [21].
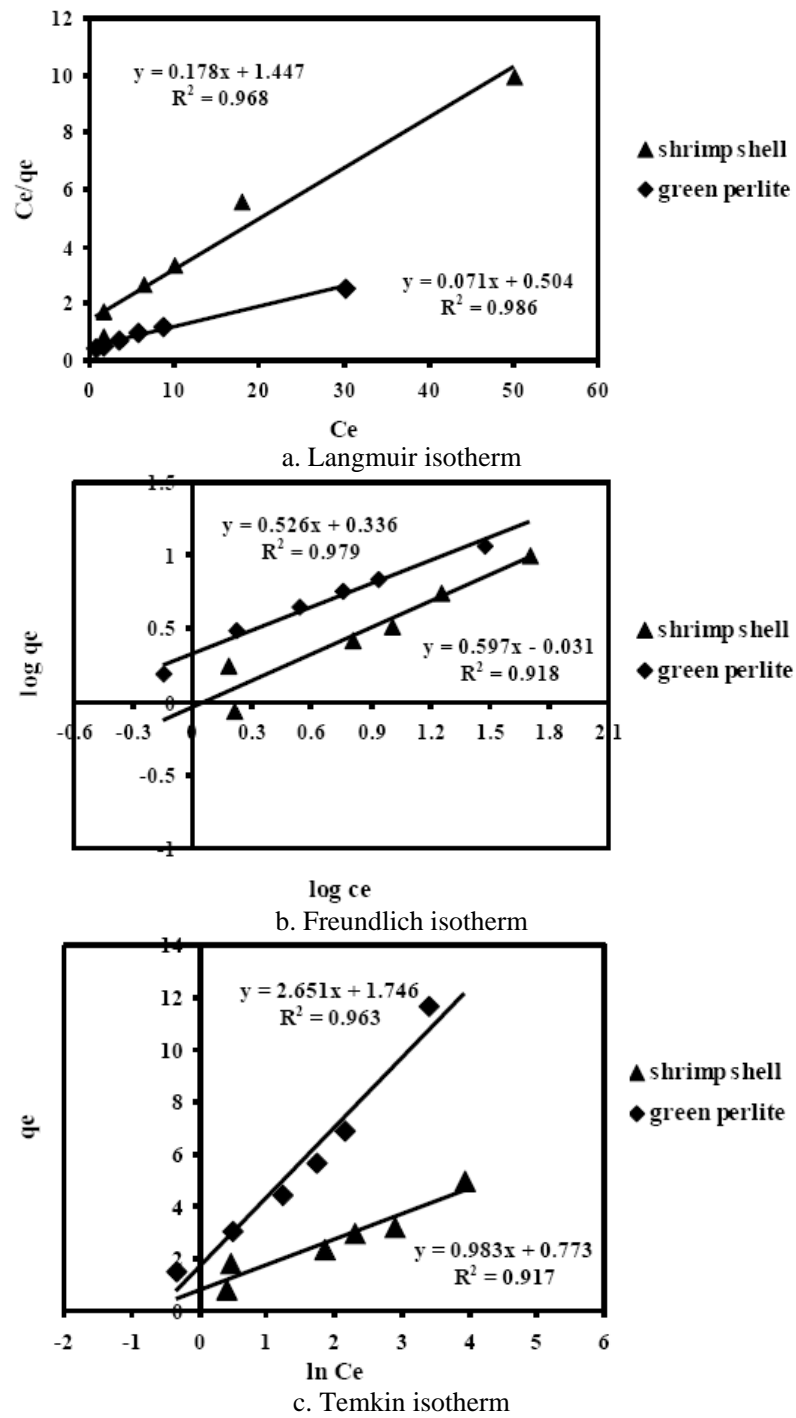

Fig. 5. Isotherm models of adsorption.

\begin{tabular}{|l|c|c|}
\multicolumn{2}{|c|}{ TABLE I: ADSORPTION ISOTHERMS } \\
\cline { 2 - 3 } \multicolumn{1}{|c|}{ Isotherms model } & \multicolumn{2}{|c|}{ Values } \\
\cline { 2 - 3 } & green perlite & shrimp shell \\
\hline Langmuir isotherm & & \\
$K_{L}(\mathrm{~L} / \mathrm{mg})$ & 0.141 & 0.123 \\
$\mathrm{q}_{\max }(\mathrm{mg} / \mathrm{g})$ & 14.085 & 5.618 \\
$R_{L}$ & $0.124-0.415$ & $0.140-0.449$ \\
$R^{2}$ & 0.986 & 0.968 \\
Freundlich isotherm & & \\
$K_{F}(\mathrm{~L} / \mathrm{mg})$ & 2.169 & 2.107 \\
$1 / \mathrm{n}$ & 0.526 & 0.597 \\
$R^{2}$ & 0.979 & 0.918 \\
Temkin isotherm & & \\
$B: R T / b_{T}$ & 2.651 & 0.983 \\
$\mathrm{~A}(\mathrm{~L} / \mathrm{mg})$ & 1.932 & 2.195 \\
$R^{2}$ & 0.963 & 0.917 \\
\hline
\end{tabular}

\section{E. Adsorption Kinetic}

In order to investigate the mechanism of adsorption, kinetic models of adsorption have been used to test experimental data. The pseudo-first order kinetic in a linear form is written as follows:

$$
\log \left(q_{e}-q_{t}\right)=\log q_{e}-\frac{k_{1} t}{2.303}
$$

When $k_{1}\left(\mathrm{~min}^{-1}\right)$ is the rate constant of pseudo-first order adsorption, $q_{e}(\mathrm{mg} / \mathrm{g})$ is the amount adsorbed at equilibrium and $q_{t}(\mathrm{mg} / \mathrm{g})$ is the amount adsorbed at any time ( $\left.\mathrm{min}\right)$. The pseudo-second order kinetic in a linear form is written as follows:

$$
\frac{t}{q_{t}}=\frac{1}{k_{2} q_{e}^{2}}+\frac{1}{q_{e}} t
$$

When $k_{2}\left(\mathrm{~g} \cdot \mathrm{mg}^{-1} \cdot \mathrm{min}^{-1}\right)$ is the rate constant of pseudo-second order adsorption. Fig. 6 shows the linear pseudo-first order kinetic and pseudo-second order kinetic of adsorption onto the adsorbents at initial dye concentration $20 \mathrm{mg} / \mathrm{L}$.
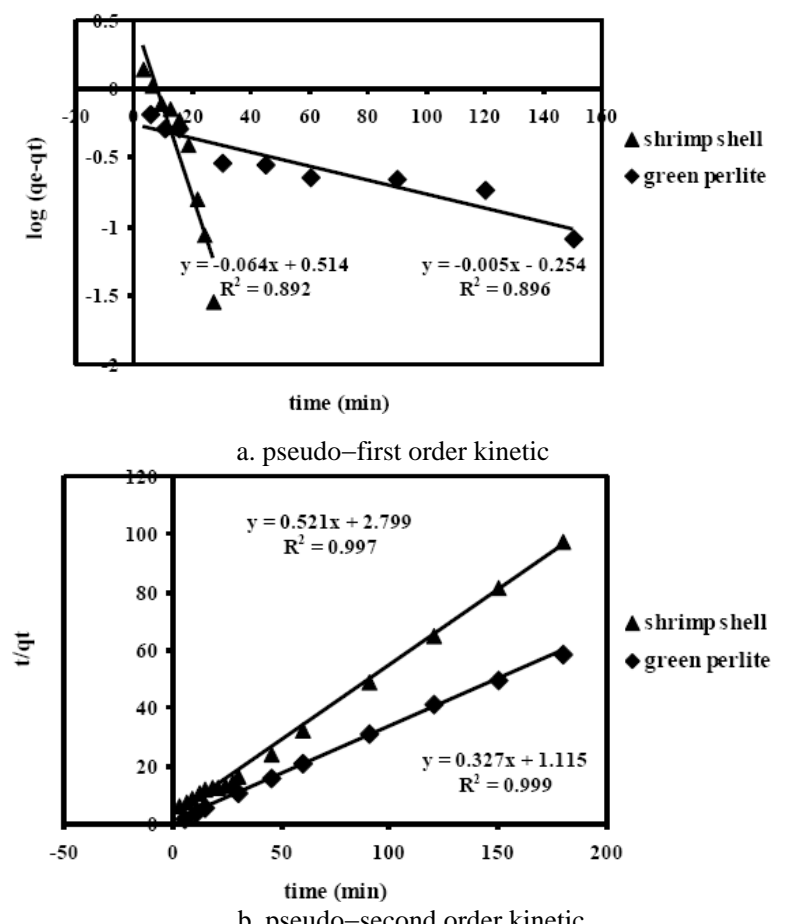

b. pseudo-second order kinetic

Fig. 6. kinetic model of adsorption.

\begin{tabular}{|l|c|c|}
\multicolumn{2}{|c|}{ TABLE II: KINETIC MODELS OF DYE } \\
\begin{tabular}{|l|c|c|}
\hline \multirow{2}{*}{ Kinetic model } & \multicolumn{2}{|c|}{ Values } \\
\cline { 2 - 3 } & green perlite & shrimp shell \\
\hline \multirow{2}{*}{$q_{e}(\mathrm{mg} / \mathrm{g})$ exp. } & 3.077 & 1.840 \\
\hline first-order & 1.092 & 3.265 \\
$q_{e}(\mathrm{mg} / \mathrm{g})$ & 0.263 & 1.184 \\
$k_{1}\left(\mathrm{~min}^{-1}\right)$ & 0.896 & 0.892 \\
$R^{2}$ & & \\
\hline second-order & 3.106 & 1.919 \\
$q_{e}(\mathrm{mg} / \mathrm{g})$ & 0.078 & 0.098 \\
$k_{2}\left(\mathrm{~g} \cdot \mathrm{mg}{ }^{-1} \cdot \mathrm{min}^{-1}\right)$ & 0.999 & 0.997 \\
$R^{2}$ &
\end{tabular} \\
\hline
\end{tabular}


The kinetic adsorption of dye on two adsorbents for initial dye concentration at $20 \mathrm{mg} / \mathrm{L}$ reached the equilibrium at 180 min for green perlite and $30 \mathrm{~min}$ for shrimp shell. As seen in Table II, the correlation coefficients of kinetic adsorption of dye onto green perlite and shrimp shell were 0.896 and 0.892 for pseudo-first order and 0.999 and 0.997 for pseudosecond order. Based on the correlation coefficient, the kinetic data were fitted better with pseudo-second order. The equilibrium adsorption capacities calculated by pseudosecond order ( $q_{e}$, cal) valued 3.106 and $1.919 \mathrm{mg} / \mathrm{g}$ for green perlite and shrimp shell, respectively. As seen from Table II, the $q_{e}$ calculated by pseudo-second order equation was closer to the experimental $q_{e}$. The pseudo-second order model is based on the assumption that the reaction is chemi-sorption involving the exchange or sharing of ions between adsorbent and adsorbate [22]. Similar observations were reported by adsorption of anionic dyes onto organo-bentonite [9] and adsorption of dye on shrimp shell [3].

\section{F. Thermodynamic Adsorption}

The thermodynamic parameter such as the Gibbs free energy change $(\Delta G)$, enthalpy change $(\Delta H)$ and entropy change $(\Delta S)$ were studied to understand better the effect of temperature on the adsorption. The experiments were performed at equilibrium time using $20 \mathrm{mg} / \mathrm{L}$ dye solutions at 25,30 and $35^{\circ} \mathrm{C}$. The Gibbs free energy of adsorption $(\Delta \mathrm{G})$ can be expressed as follows:

$$
\Delta G=-R T \ln K_{C}
$$

When $K_{C}\left(=\left[C_{\mathrm{O}}-C_{e}\right] / C_{e}\right)$ is the equilibrium constant, $R$ is the gas constant $(8.314 \mathrm{~J} / \mathrm{mol})$ and $T$ is the absolute temperature $(K)$. The enthalpy $(\Delta H)$ and entropy $(\Delta S)$ changes can be estimated by van't Hoff equation as follows:

$$
\begin{gathered}
\ln K_{C}=\frac{\Delta S}{R}-\frac{\Delta H}{R T} \\
\log K_{C}=\frac{\Delta S}{2.303 R}-\frac{\Delta H}{2.303 R T}
\end{gathered}
$$

The graph of $\log K_{C}$ versus $1 / T$ is shown in Fig. 7 and thermodynamic parameters of adsorption onto green perlite and shrimp shell are shown in Table III.

As shown in Fig. 7, the free energy of dye adsorption on green perlite and shrimp shell for initial dye concentration 20 $\mathrm{mg} / \mathrm{L}$ at the temperature 25,30 and $35^{\circ} \mathrm{C}$ were -5.464 , $-6.103,-6.776$ and $-5.721,-6.145,-6.576 \mathrm{~kJ} / \mathrm{mol}$, respectively. Whereas the temperature was raised from 25 to $35^{\circ} \mathrm{C}$, the adsorption capacity (not shown) increased from $3.002 \mathrm{mg} / \mathrm{g}$ to $3.113 \mathrm{mg} / \mathrm{g}$ for green perlite and from 1.819 $\mathrm{mg} / \mathrm{g}$ to $1.858 \mathrm{mg} / \mathrm{g}$ for shrimp shell. The negative value of $\Delta \mathrm{G}$ indicated that the dye adsorption was spontaneous in nature. Generally, the Gibbs free energy changes for physical and chemical adsorption are in the range of 0.0 to $20 \mathrm{~kJ} / \mathrm{mol}$ and 80 to $400 \mathrm{~kJ} / \mathrm{mol}$, respectively. Therefore, the adsorption of the dye onto green perlite and shrimp shell can be considered to physi-sorption in nature.

The enthalpy changes $(\Delta H)$ of dye adsorption on green perlite and shrimp shell were 18.286 and $10.722 \mathrm{~kJ} / \mathrm{mol}$, respectively. Positive value of $\Delta \mathrm{H}$ indicated the endothermic nature of the process. The entropy change $(\Delta S)$ of dye adsorption on green perlite and shrimp shell were 0.080 and $0.056 \mathrm{~kJ} / \mathrm{mol}$, respectively. Positive value of $\Delta \mathrm{S}$ indicated the increasing randomness at the solid/liquid interface during the adsorption process. Similar observation was reported by the adsorption of congo red from aqueous solutions onto Ca-bentonite [13].

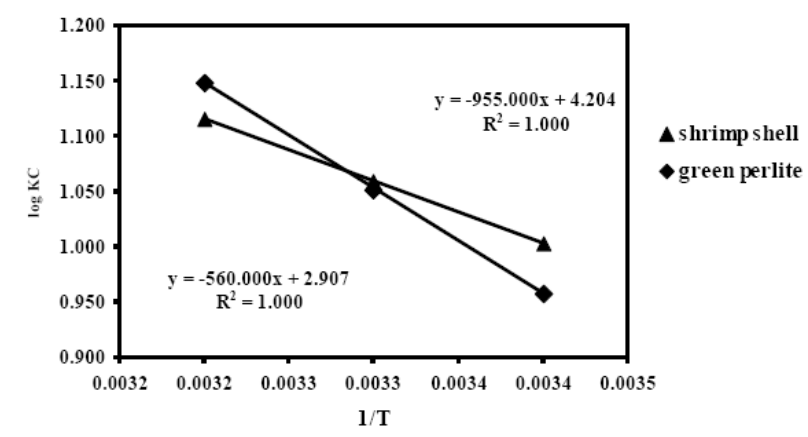

Fig. 7. Thermodynamic of dye adsorption onto green perlite and shrimp

\begin{tabular}{|c|c|c|c|c|}
\hline Adsorbents & $\begin{array}{c}\text { Temperature } \\
(\mathrm{K})\end{array}$ & $\begin{array}{l}-\Delta G \\
(\mathrm{~kJ} / \mathrm{mol})\end{array}$ & $\begin{array}{c}\Delta H \\
(\mathrm{~kJ} / \mathrm{mol})\end{array}$ & $\begin{array}{c}\Delta S \\
(\mathrm{~kJ} / \mathrm{mol})\end{array}$ \\
\hline green perlite & $\begin{array}{l}298 \\
303 \\
308\end{array}$ & $\begin{array}{l}5.464 \\
6.103 \\
6.776\end{array}$ & 18.286 & 0.080 \\
\hline shrimp shell & $\begin{array}{l}298 \\
303 \\
308 \\
\end{array}$ & $\begin{array}{l}5.721 \\
6.145 \\
6.576 \\
\end{array}$ & 10.722 & 0.056 \\
\hline
\end{tabular}
shell.

TABLE III: THERMODYNAMIC PARAMETERS

\section{CONCLUSION}

In this paper, investigation of the equilibrium adsorption of a magenta dye for silk yarn onto low-cost adsorbents, green perlite and shrimp shell, was carried out at $30^{\circ} \mathrm{C}$ in batch process. The initial rate of adsorption of dye onto green perlite and shrimp shell was high at the first $30 \mathrm{~min}$, then gradually approached the plateau. The adsorption reached equilibrium time at $180 \mathrm{~min}$ for green perlite and $30 \mathrm{~min}$ for shrimp shell. The Langmuir, Freundlich and Temkin model were used to fit the equilibrium data and estimated model parameters but the overall data was slightly better fitted by the Langmuir isotherm. The maximum adsorption capacities value $14.805 \mathrm{mg} / \mathrm{g}$ for green perlite and $5.621 \mathrm{mg} / \mathrm{g}$ for shrimp shell. The separation factor $\left(R_{L}\right)$ indicated that the adsorption was favorable. The kinetic studies showed that the adsorption of dye onto green perlite and shrimp shell followed pseudo-second order model. Thermodynamic analysis confirmed that the adsorption was a physi-sorption process. This study proved that green perlite and shrimp shell can be used as an efficient adsorbents for the removal of dye in water. Moreover, it can be concluded the use of green perlite and shrimp shell as adsorbents could contribute not only to solve the environmental problems but also to decrease the overall cost of wastewater treatment.

\section{ACKNOWLEDGMENTS}

The authors are grateful to Thepsatri Rajabhat University 
for kindly giving permission to use the equipments.

\section{REFERENCES}

[1] M. A. A. Ghouti, M. A. M. Khraisheh, S. J. Allen, and M. N. Ahmad, "Removal of dyes from textile wastewater: a study of the physical characteristics and adsorption mechanisms of diatomaceous earth," $J$. Environ Manage, vol. 69, pp. 229-238, 2003

[2] X. Han, X. Niu, and X. Ma, "Adsorption characteristics of methylene blue on poplar leaf in batch mode: Equilibrium, kinetics and thermodynamics," Korean J. Chem. Eng., vol. 29, no. 4, pp. 494-502, 2012.

[3] E. Daneshvar, M. S. Sohrabi, M. Kousha, A. Bhatnagar, B. Aliakbarian, A. Converti, and A. C. Norrstrom, "Shrimp shell as an efficient biosorbent for Acid Blue 25 dye removal from aqueous solution," $J$. Taiwan Inst Chem. E ., vol. 45, pp. 2926-2934, 2014.

[4] V. K. Gupta and Suhas, "Application of low-cost adsorbents for dye removal - A review," J. Environ Manag," vol. 90, pp. 2313-2342, 2009.

[5] K. Badii, F. D. Ardejani, M. A. Saberi, N. Y. Limaee, and S. Z. Shafaei, "Adsorption of Acid blue 25 dye on diatomite in aqueous solutions," Indian J. Technol.," vol. 17, pp. 7-16, 2010.

[6] W. H. Cheung, Y. S. Szeto, and G. McKay, "Enhancing the adsorption capacities of acid dyes by chitosan nano particles," Bioresour Technol," vol. 100, pp. 1143-1148, 2009.

[7] M. S. Tanyildizi, "Modeling of adsorption isotherms and kinetics of reactive dye from aqueous solution by peanut hull," J. Chem. Eng., vol. 168, no. 3, pp. 1234-1240, 2011.

[8] S. Hong, C. Wen, J. He, F. Gan, and Y. S. Ho. "Adsorption thermodynamics of methylene blue onto bentonite," J. Hazard. Mater. vol. 167, pp. 630-633, 2009.

[9] D. Shen, J. Fan, W. Zhou, B. Gao, Q. Yue, and Q. Kang, "Adsorption kinetics and isotherm of anionic dyes onto organo-bentonite from single and multisolute systems," J.Hazard.Mater., vol. 172, pp. 99-107, 2009.

[10] J. X. Lin, S. L. Zhan, M. H. Fang, and X. Q. Qian. "The adsorption of dyes from aqueous solution using diatomite," J. Porous. Mater., vol. 14, pp. 449-455, 2007.

[11] A. G. Hadi, "Adsorption of (Cd) ions by synthesize chitosan from fish shells," BJS, vol. 5, no. 2, pp. 33-38, 2012.

[12] A. Kamari, W. S. Wan Ngah, and L. K. Liew, "Chitosan and chemically modified chitosan beads for acid dyes sorption," J. Environ. Sci., vol. 21, pp. 296-302, 2008.

[13] L. Lian, L, Guo, and C. Guo, "Adsorption of congo red from aqueous solutions onto Ca - bentonite," J. Hazard. Mater, vol. 16, pp. 126-131, 2009.

[14] K. Fytianos, E. Voudrias, and E. Kokkalis, "Sorption-desorption behavior of 2,4-dichlorophenol by marine sediments," Chemosphere, vol. 40, pp. 3-6, 2000.
[15] S. M. Ahmed, F. I. El-Dib, N. S. E. Gendy, W. M. Sayed, and M El-Khodary. A kinetic study for the removal of anionic sulphonated dye from aqueous solution using nano-polyaniline and Baker's yeast Arabian Journal of Chemistry. [Online]. pp. 1-8 Available: http://dx.doi.org/10.1016/j.arabjc.2012.04.049.

[16] S. C. Ibrahim, M. Hanafiah, and M. Z. A.Yahya, "Removal of Cadmium from Aqueous Solutions by using Low-Cost by Adsorption onto Sugarcane Bagasse," J. Agric \& Environ. Sci., vol. 1, no. 3, pp. 179-184, 2006

[17] X. J. Hu, J. S. Wang, Y. G. Liu, X. Li, G. M. Zeng, Z. L. Bao, X. X Zeng, A. W. Chen, and F. Long "Adsorption of chromium(VI) by ethylenediamine-modified cross-linked magnetic chitosan resin: Isotherms, kinetics and thermodynamics," J. Hazard. Mater., vol. 185, pp. 306-314, 2011

[18] E. Errais, J. Duplay, F. Darragi, I. M'Rabet, A. Aubert, F. Huber, and G. Morvan, "Efficient anionic dye adsorption on natural untreated clay:Kinetic study and thermodynamic parameters," Desalination., vol. 275, pp. 74-81, 2011.

[19] S. Kaur, S. Rani, and R. K. Mahajan. (2013). Adsorption Kinetics for the Removal of Hazardous Dye Congo red by Biowaste Materials as Adsorbents. Journal of Chemistry. [Online]. pp. 1-12 Available: http://www.hindawi.com/journals/jchem/2013/628582/

[20] A. U. Itodo and H. U. Itodo, "Sorption Energies Estimation Using Dubinin-Radushkevich and Temkin Adsorption Isotherms," Life Science J., vol. 7, pp. 31-39, 2010.

[21] E. Bulut, M. Ozacar, and I. A. Sengil, "Adsorption of malachite green onto bentonite: Equilibrium and kinetic studies and process design," Microporous Mesoporous Mater., vol. 115, pp. 234-246, 2008.

[22] K. V. Kumar, "Comments on Adsorption of acid dye onto organobentonite," J. Hazard. Mater, vol. B137, pp. 638-639, 2006.

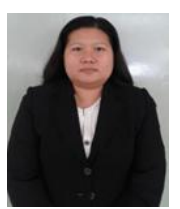

Suchada Sawasdee was born in Lopburi, Thailand. She graduated in bachelor degree of chemistry from Faculty of Science and Technology, Thepsatri Institute, Lopburi, Thailand and master degree of biotechnology from Faculty of Biotechnology, Rangsit University, Thailand. She worked at Thepsatri Rajabhat University, as a lecturer in Department of Chemistry, Faculty of Science and Technology, Lopburi, Thailand. Her research topics are adsorption on natural inorganic material and agriculture waste.

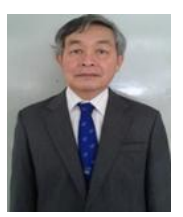

Prachart Watcharabundit was born in Chumporn, Thailand. He graduated in bachelor and master degree in chemistry from Srinakarinwirot University, Bangkok, Thailand. He worked at Thepsatri Rajabhat University, Thailand as a lecturer (Asst. Prof.) in Department of Chemistry, Faculty of Science and Technology, Lopburi, Thailand. His research topics are adsorption, ion exchange on activated carbon, natural adsorbent and agriculture waste. 